\title{
Investigating the potential synergistic interactions between whole fruits and vegetables
}

Synergism is defined as a combination of two or more substances, to produce a collective effect greater than each agent separately ${ }^{(1)}$. It has been reported that combinations of different phenolic compounds, in fruit smoothies, can result in synergistic antioxidant effects $^{(2)}$. The objective of the present study is to determine the effect of potential synergistic interactions between fruits and vegetables (FV) on their antioxidant and anti-cariogenic activities.

Whole FV including blueberry, red grape, strawberry, red pepper, sweet potato (with and without skin), carrot and garlic were analysed both individually and combined. Antioxidant activity was assessed using the DPPH radical scavenging ${ }^{(3)}$, total phenolic content $(\mathrm{TPC})^{(4)}$ and ferric reducing antioxidant power (FRAP) ${ }^{(5)}$ assays. Anti-cariogenic activity was determined using a standard agar well diffusion method of measuring growth inhibition of the pathogen Streptococcus mutans ${ }^{(6)}$.

Red grape and carrot individually were found to have lowest radical scavenging activity ( $68 \pm 1.81 \%$ and $33 \pm 5.79 \%$, respectively), but when combined, the antioxidant potential significantly $(\mathrm{p} \leq 0.05)$ increased to $93 \pm 0.91 \%$. Whole blueberry exhibited greatest radical scavenging activity $(96 \pm 0.46 \%)$, however when combined with strawberry, the antioxidant activity significantly decreased ( $\mathrm{p} \leq$ 0.05), indicating an antagonistic effect. A similar antagonistic effect was observed for combinations of sweet potato (without skin) and carrot in the FRAP assay, with reduction ability significantly $(\mathrm{p} \leq 0.05)$, decreasing from $17.8 \pm 2.25 \mu \mathrm{M} \mathrm{Fe} e^{2+} / \mathrm{g}_{\mathrm{fw}}$ and $8.6 \pm 0.95 \mu \mathrm{M}$ $\mathrm{Fe}^{2+} / \mathrm{g}_{\mathrm{fw}}$ (respectively), to $6.81 \pm 0.63 \mu \mathrm{M} \mathrm{Fe}^{2+} / \mathrm{g}_{\mathrm{fw}}$ when combined. Red pepper possessed greatest TPC $\left(488 \pm 62.6 \mathrm{mg} \mathrm{GAE} / 100 \mathrm{~g}_{\mathrm{fw}}\right)$ but in combination with blueberry, it significantly decreased $(\mathrm{p} \leq 0.05)$, to $181 \pm 6.76 \mathrm{mg}$ GAE/100g $\mathrm{g}_{\mathrm{fw}}$. None of the individual FV displayed anti-cariogenic activity against $S$. mutans. However, the FV combination of sweet potato (without skin) and blueberry inhibited the growth of $S$. mutans, in a dose-dependent manner.

Data from this study indicate that the antioxidant activity of FV can be both positively and negatively affected by combining FV. Furthermore, while no individual FV possessed anti-cariogenic activity, certain FV combinations showed antimicrobial activity against $S$. mutans.

1. Bijnsdorp IV, Giovannetti E \& Peters GJ (2011) Methods Mol Biol 731:421-34

2. McCarthy AL, O’Callaghan YC, Neugart S et al. (2013) Food Chem 141:2567-2574.

3. Blois MS (1958) Nature 181:1199-1200.

4. Singleton VL \& Rossi JA (1965) Amer. J. Enol. Viticult 16:144-158.

5. Benzie IFF \& Strain JJ (1996) Anal. Biochem. 239:70-76.

6. Dinesh MD, Shaheena A, Abdul Bari KK et al. (2016) Int J Curr Microbiol App Sci 5(1):699-705. 